\title{
MERANCANG KARAKTER DALAM CERITA RAKYAT KERAJAAN BANTARANGIN SEBAGAI SEJARAH TERCIPTANYA KESENIAN REOG PONOROGO
}

\author{
Suryani dan Santi Sidhartani \\ Program Studi Desain Komunikasi Visual \\ Fakultas Bahasa dan Seni, Universitas Indraprasta PGRI \\ Jl. Nangka No. 58 C, Tanjung Barat, Jakarta 12530, Indonesia
}

\begin{abstract}
Abstrak
Kerajaan Bantarangin merupakan cerita rakyat masyarakat Ponorogo yang telah turun menurun diwariskan, perannya sebagai naskah pementasan dan cerita asal-usul kesenian Reog Ponorogo membuat cerita rakyat ini patut dilestarikan melalui media buku ilustrasi. Dalam pembuatannya buku ilustrasi berlandaskan sebuah cerita tentunya memiliki karakter yang menjadi fokus utama dalam berjalanya cerita. Dengan menggunakan teori bentuk dasar persegi, lingkaran dan segitiga penulis dapat memberikan kesan watak karakter pada pembaca dan memberi sugesti secara tidak langsung yang mempengaruhi persepsi pembaca, karenanya penulis memperaktikan teori tersebut dengan harapan untuk dapat membuat buku yang menarik dan dapat mengkomunikasikan isi cerita dengan baik
\end{abstract}

Kata kunci: Kerajaan Bantarangin, Reog Ponorogo, Cerita Rakyat.

\begin{abstract}
Bantarangin kingdom is a folklore of Ponorogo's people that have been told trough generation, it's role as the script and the origin of Reog Ponorogo performance art make this folklore deserve to be preserve in the form of illustration book. In the making of the illustration book that based on a story, it sure to have some character that become the focus of the on going story. Following the guide of basic shape theory in wich rectangle, circle and triangle are use to give the reader indirect suggestion about the character's personality to effect the reader's perspective toward the character without obvious signs. Therefor, writer would like to try to use those theory inorder to make the illustration book interesting, and communicate more effectively.
\end{abstract}

Keyword: Bantarangin kingdom, Reog Ponorogo, folklore.

\section{PENDAHULUAN}

Reog Ponorogo merupakan kesenian tari rakyat asal kota Ponorogo Jawa Timur yang mementaskan iring-iringan penari berupa jathilan (sejenis kuda lumping), tari topeng dhadak merak yang berupa topeng raksasa berbahan dasar bambu berhias bulu merak dengan kepala macan yang beratnya mencapai puluhan kilo dengan tinggi sekitar 2 meter, serta aksi teaterikal Kerajaan Bantarangin yang mementaskan kisah cinta Raja Kelono Sewandono dengan Putri Dewi Songgolangit. 


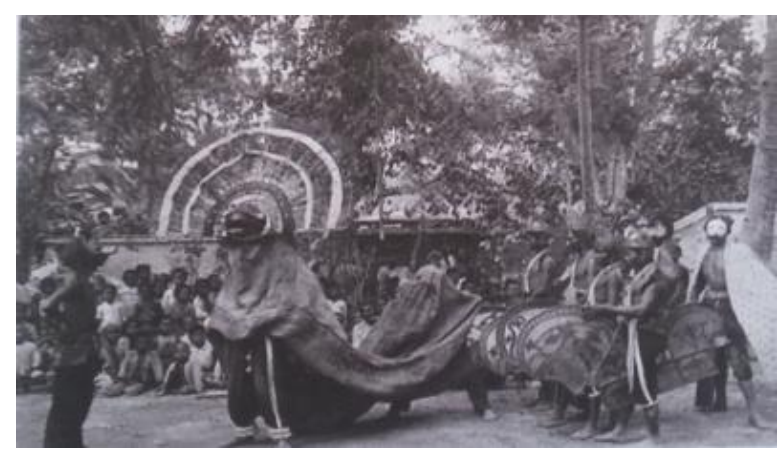

Gambar 1 Pementasan Reog Ponorogo tahun 1920 (dari kiri ke kanan tokoh Kelono Sewandono, Singobarong, dan jathilan) Sumber: Soemarto (2014: 13)

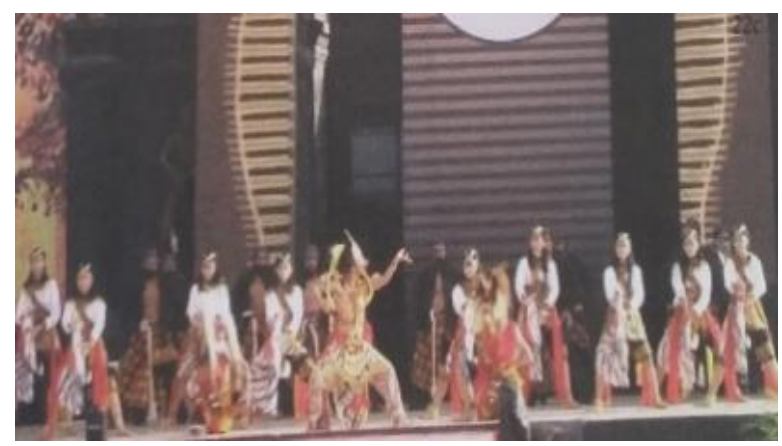

Gambar 2 Pementasan Reog Ponorogo tahun 2014 (jaman sekarang) Sumber: Somearto (2014: 65)

Lahir sejak tahun $1235 \mathrm{M}$ pada mulanya Reog Ponorogo merupakan kisah yang didongengkan di dalam istana, namun menyebar ke masyarakat dan masyarakat sangat menyukainya, sejak itulah kesenian Reog Ponorogo berkembang (Soemarto, 2014:14).

Kerajaan Bantarangin adalah cerita rakyat (folklore) yang digunakan dalam naskah pementasan Reog Ponorogo dan dijadikan media pembelajaran tentang asal-usul kesenian Reog Ponorogo yang mendunia. Kerajaan Bantarangin diperintah oleh rajanya yang bernama Kelono Sewandono dan patihnya Bujangganong yang melamar putri Kediri, Dewi Songgolangit. Dengan seserahan yang diminta Dewi Songgolangit sehingga terciptanya kesenian Reog Ponorogo.

Menurut Sujud (2017:52), Nama Bantarangin berasal dari kata banter angin (angin yang kencang), yaitu suatu tempat datar yang anginnya sangat kencang. Kerajaan Bantarangin selalu digambarkan sebagai kerajaan yang besar dengan raja muda yang tampan dan rakyat yang makmur.

Sebagai kesenian yang telah mendunia masih banyak yang belum mengetahui mengenai asal-usul Reog Ponorogo, hal ini dikarenakan Reog Ponorogo merupapakan salah satu kesenian daerah dari Indonesia yang belum banyak dibukukan, penyampaiannya dari cerita tutur yang dilakukan secara turun-temurun oleh para pendahulu (Soemarto, 2014:04). Kurangnya pengakuan, pembukuan dan media yang menggunakan Kerajaan Bantarangin dan Reog ponorogo sebagai objeknya pernah menjadi masalah besar bagi pemerintah Indonesia saat Malaysia mengakui Reog Ponorogo sebagai kesenian asli Malaysia.

\section{METODE PENELITIAN}

Metode penelitian yang digunakan dalam penelitian ini adalah jenis penelitian kualitatif. Untuk memperoleh data, peneliti menggunakan beberapa metode yang disesuaikan pada jenis penelitian kualitatif dengan cara, antara lain: 


\section{Studi Pustaka}

Pengumpulan data yang menggunakan referensi buku, jurnal, dan website yang berkaitan pada materi yang mendukung penelitian ini.

\section{Observasi}

Observasi dilakukan pada daerah asal cerita rakyat Kerajaan Bantarangin yaitu kota Ponorogo Jawa Timur, dengan mengamati langsung bagaimana cerita rakyat Kerajaan Bantarangin dipentaskan dalam pementasan Reog Ponorogo Pada Festifal Reog Nasional Grebeg Sura, menganalisa bagaimana sebuah cerita rakyat menjadi bagian dari kegiatan masyarakat dan pengaplikasian pesan moral yang dapat dipetik dari cerita tersebut. Mengamati atribut dan kostum sebagai inspirasi pembuatan karakter.

\section{Wawancara}

Wawancara dilakukan dengan bapak Yudi Irawan S. Hum. Selaku staff pembukuan naskah kuno Perpustakaan Nasional Republik Indonesia, Untuk mendapatkan data mengenai keberadaan cerita rakyat Kerajaan Bantarangin di masyarakat kota Ponorogo bagaimana cerita rakyat berkembang pada masanya dan bertahan hingga sekarang.

\section{PEMBAHASAN}

\section{Penggambaran tokoh karakter}

Setiap cerita memiliki tokoh atau karakter utama yang berperan dalam penyampaian cerita dan berjalannya alur.

Menurut Pratama, dkk. (2017: 294-295), untuk merancang karakter visual, sebuah gaya visual dibutuhkan. Gaya visual yang merupakan hasil dari ilustrasi yang mana merupakan elemen yang sangat penting dalam perancangan. Ilustrasi sering dikaitkan dengan "citra" yang dapat menyajikan sebuah kesan melalui gabungan dari elemen garis, bentuk tekstur dan warna. Ilustrasi dengan penggayaan karakter tertentu pada karakter visual yang dianggap dapat mewakili ide tentang nilai kebudayaan sosial. Narasi visual dapat disajikan dengan melihat berbagai aspek dari kehidupan manusia. Kapan itu berkembang, dari aspek psikologi, politik, dan budaya sosial. Yang bergantung pada pesan yang ingin disampaikan sepanjang lini cerita.

Beiman (dalam Pratama, dkk. 2017: 294-295) mengutarakan bahwa, elemen visual dari bentuk yang juga dapat digunakan untuk memberi perbedaan pada elemen internal karakter, bentuk yang tidak hanya dapat membuat karakter nampak berbeda tapi juga memiliki konotasi dari tipe personalitas karakter di antaranya:

1. Lingkaran, konotasi dari lingkaran cenderung menggambarkan usia muda dan kebaikan, mengkomunikasikan ide seperti bermain, kekanak-kanakan, kepolosan, sikap positif, keseimbangan, keutuhan, kesatuan, perlindungan dan alam.

2. Bentuk Segitiga mengkomunikasikan ide tentang kestabilan, kekuatan, dan ketidakstabilan. Makna yang dapat digabungkan dalam kategori- kategori yaitu, kategori energi (ekspresi dinamik, kecepatan, dan ketidaktepatan) dan kategori temperamen (ekspresi dari kesabaran, agresi, hostilitas, dan seksualitas).

3. Kotak, bentuk mengotak memberi kesan kekuatan stabil yang diasosiasikan dengan maskulinitas, keamanan, rasionalitas, ajaran kebenaran, dan kemurnian.

Tokoh atau karakter utama yang ada di dalam cerita rakyat Kerajaan Bantarangin diantaranya:

\section{Raja Kelono Sewandono}

Kelono Sewandono adalah raja muda Kerajaan Bantarangin yang masih jejaka, tampan dan digdaya, ia raja yang sakti mandraguna dan memiliki sebuah pusaka andalan berupa cemeti bernama pecut Samandiman (Sujud, 2007: 47-48). Raja Kerajaan Bantarangin Raja muda yang arif, gagah perkasa, tampan, dan cerdik, digambarkan memiliki wajah tampan dan gagah perkasa, 
menggambarkan karakter kesatria yang gigih berjuang dan juga bekerja cerdik dalam menempuh ujian. Menurut Hidayanto (2012: 2135), Klono Sewandono adalah raja kerajaan Bantarangin. Sosok ini digambarkan dengan topeng bermahkota, wajah berwarna merah, mata besar melotot, dan kumis tipis dengan rambut panjang. Selain itu ia membawa Pecut Samandiman, berbentuk tongkat lurus dari rotan berhias jebug dari sayet warna merah diseling kuning sebanyak 5 atau 7 jebug.

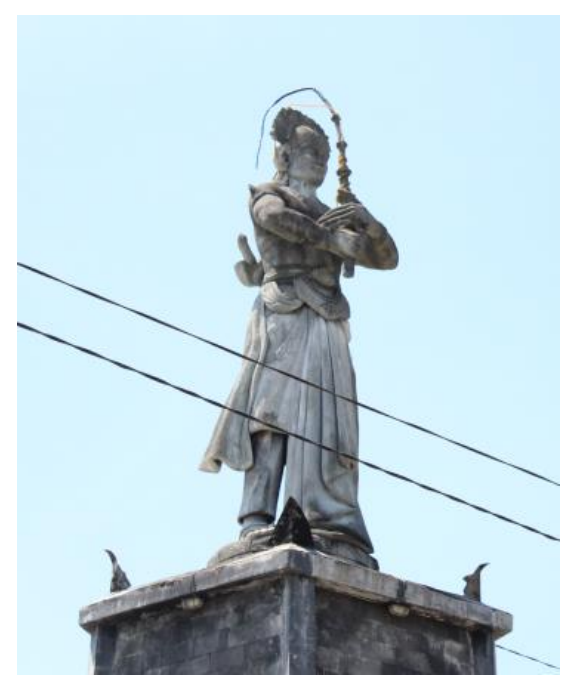

Gambar 3 Patung Kelono Sewandono di Monument bantarangin Sumber: dokumentasi pribadi

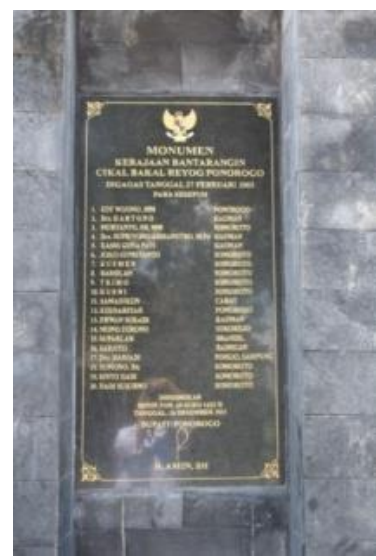

Gambar 4 Peresmian monument bantarangin

Sumber: dokumentasi pribadi

Ciri penggambaran berikut juga telah diwujudkan dalam patung monumen yang diresmikan oleh pemerintah dan petuah Ponorogo dengan didirikannya monumen Bantarangin di Kauman pada tahun 2003 ini menggunakan struktur kotak (square) yang memberi kesan psikologis kestabilan dan maskulinitas. 


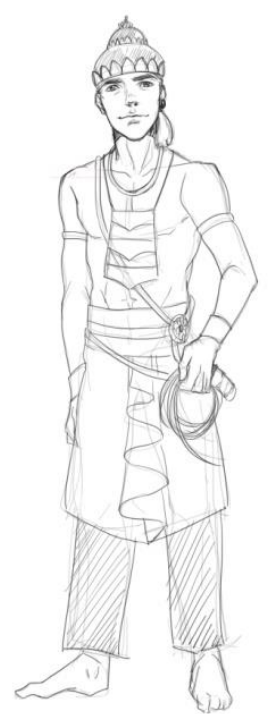

Gambar 5 Sketsa perancangan karakter Raja Kelono Sewandono Sumber: dokumentasi pribadi

Selain itu, pola persegi ditempatkan pada bagian-bagian tubuh yang menjadi fokus pengelihatan atau interest point, $d \mathrm{i}$ antaranya bahu, wajah dan mata.

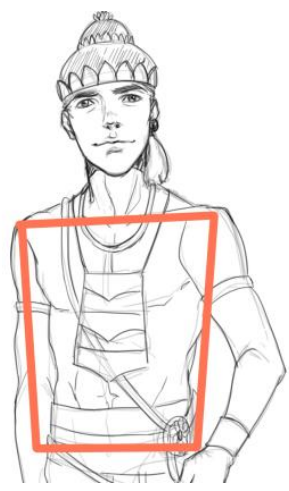

Gambar 5 Sketsa perancangan karakter Raja Kelono Sewandono Sumber: dokumentasi pribadi

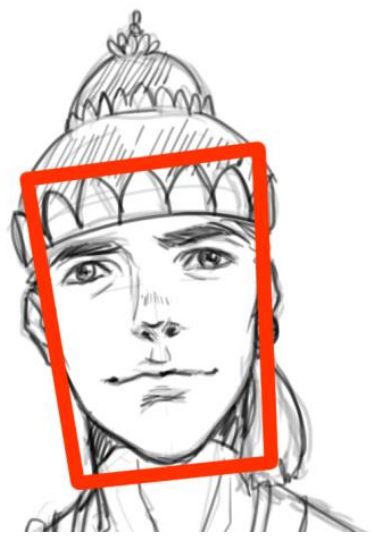

Gambar 6 Sketsa perancangan karakter Raja Kelono Sewandono Sumber: dokumentasi pribadi 
Gambar 7 Sketsa perancangan karakter Raja Kelono Sewandono

Sumber: dokumentasi pribadi

Pengulangan pola persegi pada sketsa karakter Kelono Sewandono juga menjadi sebuah harmoni dalam bentuk repetisi yang menyatukan keseluruhan anatomi.

\section{Dewi Songgolangit}

Dewi Songgolangit adalah putri Raja Kediri yang terkenal keelokan dan kecantikannya. oleh karena itu, banyak raja dari berbagai tempat yang ingin meminang putri Kerajaa Kediri tersebut. Salah satu raja tersebut adalah Prabu Kelono Sewandono dari Kerajaan Bantarangin, yang kemudian mengutus Patih Bujangganong untuk melamar putri tersebut (Sujud, 2007:49).

Berdasarkan data yang ada mengenai karakter dapat dilihat penggayaan bentuk yang sesuai dengan karakter Dewi Songgolangit bentuk dasar lingkaran yang menggambarkan kecantikan, keutuhan, dan kepolosan seorang putri raja yang disesuaikan dengan referensi visual dari monumen patung yang ada di Ponorogo.

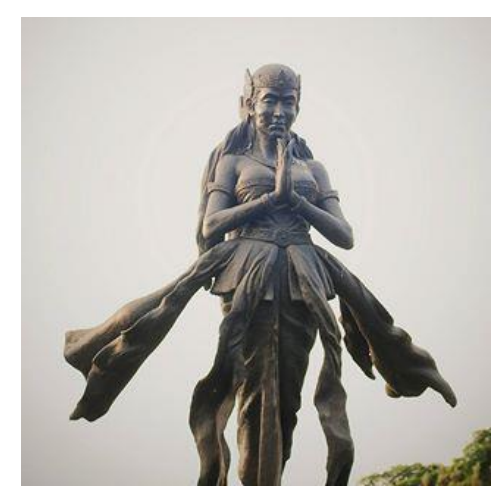

Gambar 8 Tugu monumen Kerajaan Bantarangin dengan Dewi Songgolangit diatasnya Sumber: Soemarto (2014: 12)

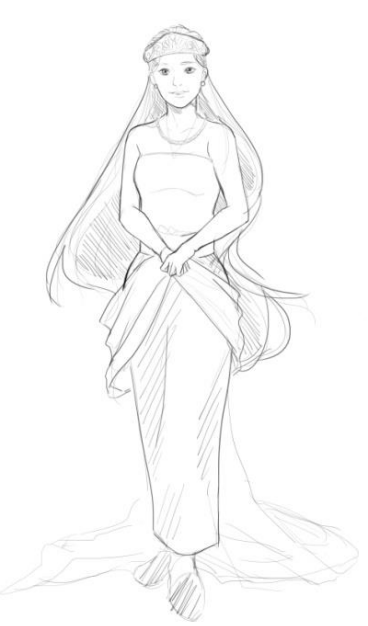

Gambar 9 Sketsa karakter Dewi Songgolangit

Sumber : dokumentasi pribadi 


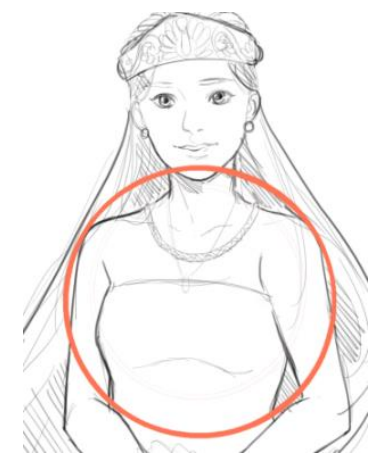

Gambar 10 Sketsa karakter Dewi Songgolangit Sumber : dokumentasi pribadi

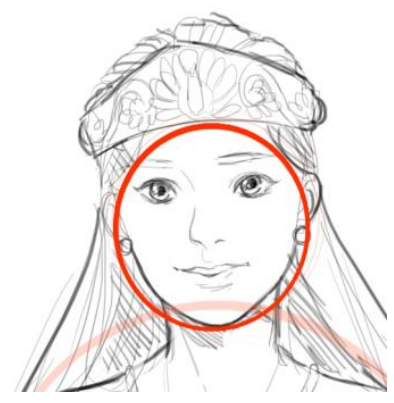

Gambar 16 Sketsa karakter Dewi Songgolangit Sumber : dokumentasi pribadi

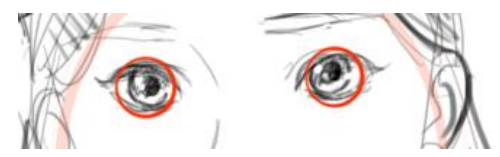

Gambar 11 Sketsa karakter Dewi Songgolangit Sumber : dokumentasi pribadi

Sama seperti dalam perancangan karakter Kelono Sewandono, Keseluruhan pola lingkaran juga digunakan pada perancangan karakter Dewi Songgolangit, guna memberikan harmoni dan memberikan kesan yang ingin di sampaikan yaitu cantik, lembut dan polos.

\section{Singobarong (tokoh antagonis)}

Menurut Sujud (2007: 49), Singobarong (Singalodra) adalah seorang Raja dari Kerajaan Lodaya yang merupakan pesaing atau rival Prabu Kelana Sewandana untuk melamar Dewi Sanggalangit di Kediri. Persaingan tersebut berubah menjadi perang yang hebat. Dalam peperangan tersebut, kedua belah pihak menunjukkan kesaktiannya. Raja Singalodra sangat sakti, ia dapat mengubah diri menjadi harimau yang menakutkan. Memang, tokoh itu berwujud manusia yang berwajah menyerupai singa atau harimau. 


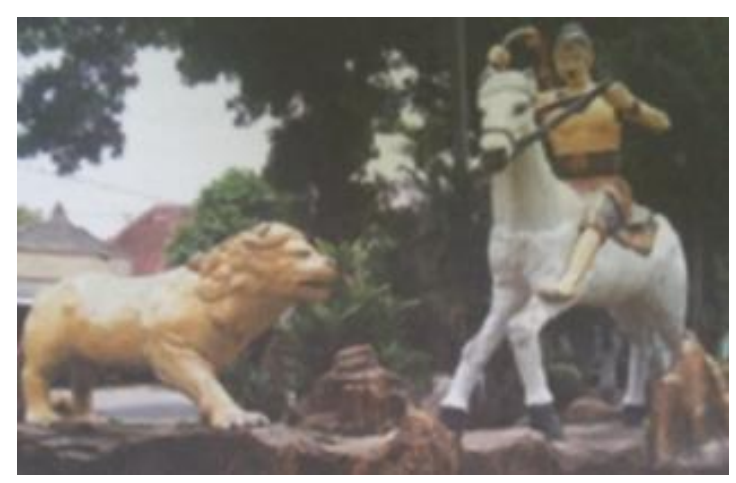

Gambar 12 Patung di alun-alun kota ponorogo menggabarkan pertarungan singobarong dan kelonosewandono

Sumber: Soemarto (2014: 13)

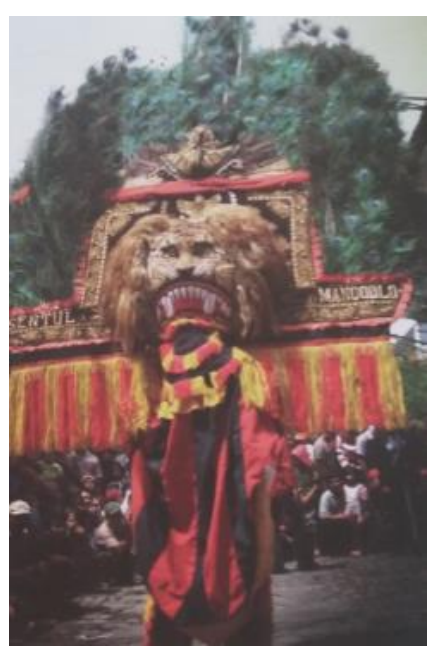

Gambar 13 Kostum singgobarong pada pementasan Reog Ponorogo

Sumber: Soemarto (2014: 46)

Berdasarkan deskripsi tersbut dapat disimpulkan karakteristik fisik tokoh Singobarong yang merupakan manusia perkasa yang dapat dirancang menggunakan pola dasar segitiga yang melambangkan ketidakstabilan emosi, agresifitas, dan watak keras kepala dan presisten pada karakter.

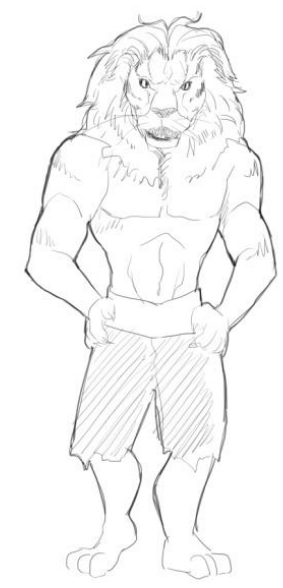

Gambar 14 Sketsa karakter singobarong

Sumber : dokumentasi pribadi 


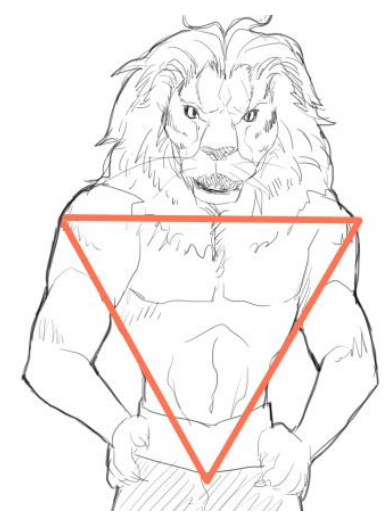

Gambar 15 Sketsa karakter singobarong

Sumber : dokumentasi pribadi

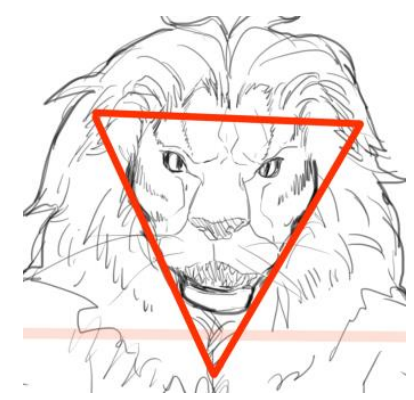

Gambar 16 Sketsa karakter singobarong

Sumber : dokumentasi pribadi

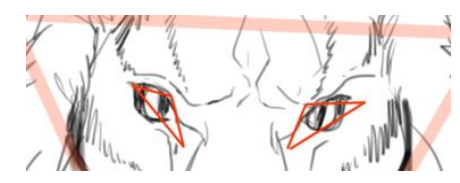

Gambar 17 Sketsa karakter singobarong

Sumber : dokumentasi pribadi

\section{SIMPULAN}

Kerajaan Bantarangin merupakan cerita rakyat yang telah mendarah daging di masyarakat Ponorogo, Ceritanya yang digunakan dalam pementasan kesenian Reog yang telah mendunia dan kaya akan keberagaman karakter dan latar belakang sejarah karenanya kisah ini sangatlah menarik untuk dikaji. Dari beragam karakter yang ada pada cerita ini terdapat tiga karakter utama yang menjadi fokus dalam cerita yaitu Raja Kelono Sewandono, Putri Dewi Songgolangit dan, Raja Singobarong.

Dalam penyajiannya sebuah buku ilustrasi sangatlah mengandalkan pesan tersirat melalui gambar dan salah satu cara untuk memberikan pesan ini adalah dengan melalui penggambaran karakter yang dalam hal ini menggunakan perinsip bangun dasar persegi, lingkaran dan segitiga guna menggambarkan sebuah kekokohan melalui persegi pada karakter Kelono sewandono, kelembutan melalui lingkaran pada pola karakter Dewi songgolangit, dan segitiga untuk menggambarkan ketidak stabilan emosi raja Singobarong. 
Adapun saran dan masukan kepada pemerintah Indonesia dan kota Ponorogo khususnya agar dapat senantiasa menjaga dan melestarikan cerita rakyat Reog Ponorogo dengan melibatkan kaum muda agar budaya dapat terus dilanjutkan ke generasi selanjutnya, bagi anak Indonesia juga di harapkan untuk lebih peduli terhadap budaya penuh nilai dan makna yang kita miliki dan untuk turut bangga dan mengambil andil dalam pengembangannya.

\section{DAFTAR PUSTAKA}

Hidayanto, A. F. (2012). Topeng Reog Ponorogo dalam Tinjauan Seni Tradisi. Jurnal Eksis, 8(1), 213-238.

Pratama, D., Gunarti, W., \& Akbar, T. (2017). Understanding visual novel as artwork of visual communication design. Mudra Jurnal Seni Budaya, 32(3). 292-298.

Soemarto. (2014). Menelusuri Perjalanan Reog Ponorogo. Ponorogo: CV. Kotareog Media.

Sujud, S.P.J. (2017). Kajian Historis Legenda Reog Ponorogo. BAHASA DAN SENI, 35(1), hlm. 41-57. Retrived from: http://sastra.um.ac.id/wp-content/uploads/2009/10/KajianHistoris-Legenda-Reyog-Ponorogo.pdf 